\title{
HIGH RESOLUTION BREAKPOINTS OF THE PHILADELPHIA TRANSLOCATION IN PATIENTS WITH CHRONIC MYELOGENOUS LEUKEMIA
}

\author{
Shinichi Misawa, ${ }^{1}$ Shoichiro Tsuda, ${ }^{1}$ Masafumi Taniwaki, ${ }^{1}$ \\ Tatsuro TAKIno, ${ }^{1}$ and Tatsuo ABE ${ }^{2}$ \\ ${ }^{1}$ Third Department of Medicine, and ${ }^{2}$ Department of Hygiene, \\ Kyoto Prefectural University of Medicine, \\ Kyoto 602, Japan
}

\begin{abstract}
Summary The breakpoints of the Philadelphia $(\mathrm{Ph})$ translocation were studied precisely with high resolution chromosome banding in 19 patients with chronic myelogenous leukemia $(\mathrm{CML})$. The cultures were treated with ethidium bromide to obtain elongated and finely banded chromosomes. In five cases chromosomes were examined at 850 bands/haploid set of chromosome stage and the $\mathrm{Ph}$ breakpoints were specified on $9 \mathrm{q} 34.11$ band and $22 q 11.21$ band. The remaining 14 cases revealed the breakpoints on bands $9 \mathrm{q} 34.1$ and $22 \mathrm{q} 11.2$ at $550-650$ band stage of mitosis. The data indicate that the $\mathrm{Ph}$ breakpoints are identical in all the 19 cases of CML.
\end{abstract}

\section{INTRODUCTION}

Recent technological advances in cytogenetics and molecular biology showed that the Philadelphia (Ph) chromosome (Nowell and Hungerford, 1960) is the result of a reciprocal translocation between one chromosome $\# 9$ and one chromosome \#22 in most cases (standard translocation) (Rowley, 1973; Groffen et al., 1983), but in the remaining cases the $\mathrm{Ph}$ translocation involves chromosomes $\# 9$, \#22, and at least one other chromosome (complex translocation) (Hagemeijer et al., 1984; Mitelman, 1985). Whether the $\mathrm{Ph}$ translocation is the standard type or the complex type, these rearrangements consistently result in a translocation of a chromosomal segment from chromosome $\# 9$ to $\# 22$ (Hagemeijer et al., 1984). In association with this translocation one of proto-oncogenes, c- $a b l$, is translocated from chromosome $\# 9$ to \#22 (Klein et al., 1982; Hagemeijer et al., 1984). Interestingly, several investigators have shown the variety in the size of the Ph chromosome by banding chromosome analysis (Watt et al., 1977; Verma and Dosik, 1980), which means the breakpoint

Received June 11, 1987; Accepted August 11, 1987 
may differ among different cases. We attempted to specify the breakpoints of the $\mathrm{Ph}$ translocation with elongated and finely banded chromosomes.

\section{MATERIALS AND METHODS}

Bone marrow or peripheral blood cells were obtained from 19 patients with chronic myelogenous leukemia (CML). The cells were cultured in RPMI 1640 medium supplemented with $15 \%$ fetal bovine serum for $24 \mathrm{hr}$ at $37^{\circ} \mathrm{C}$ without mitogen. To obtain elongated and finely banded chromosomes, ethidium bromide was added to the culture for the last two hours at a final concentration of $10 \mu \mathrm{g} / \mathrm{ml}$ and Colcemid was added for $15 \mathrm{~min}$ before harvesting the cells $(0.05 \mu \mathrm{g} / \mathrm{ml}$ ) (Misawa et al., 1986). Chromosome preparations were made by air drying method and G-banding was performed. Chromosome identification and karyotype designation were done according to the International System for Human Cytogenetic Nomenclature (1985).

\section{RESULTS}

All patients showed a standard or a complex Ph translocation (Table 1). The complex translocations seen in these patients were $t(9 ; 22 ; 15)(\mathrm{q} 34.1 ; \mathrm{q} 11.2 ; \mathrm{q} 22.1)$ in

Table 1. High resolution breakpoints of $\mathrm{Ph}$ translocation in patients with chronic myelogenous leukemia.

\begin{tabular}{|c|c|c|c|c|c|}
\hline Case No. & Name & Age & Sex & $\begin{array}{l}\text { Mitotic stage, } \\
\text { bands/haploid }\end{array}$ & $\begin{array}{l}\text { Breakpoints }^{\mathrm{a}} \text { of } \\
\text { chromosome } 9 \& 22\end{array}$ \\
\hline $1 \mathrm{~b}$ & M. K. & 47 & $\mathrm{M}$ & 550 & $9 \mathrm{q} 34.1 / 22 \mathrm{q} 11.2$ \\
\hline 2 & $\mathrm{~K} . \mathrm{K}$. & 30 & $\mathrm{~F}$ & 550 & $9 q 34.1 / 22 q 11.2$ \\
\hline 3 & Y. H. & 56 & $\mathrm{~F}$ & 550 & $9 \mathrm{q} 34.1 / 22 \mathrm{q} 11.2$ \\
\hline 4 & $\mathrm{~T} \cdot \mathrm{K}$. & 62 & $\mathrm{~F}$ & 550 & $9 q 34.1 / 22 q 11.2$ \\
\hline 5 & $\mathrm{~T} \cdot \mathrm{M}$ & 44 & $\mathrm{M}$ & 650 & $9 \mathrm{q} 34.1 / 22 \mathrm{q} 11.2$ \\
\hline $6 b$ & $\mathrm{Y} \cdot \mathrm{T}$. & 31 & $\mathrm{~F}$ & 550 & $9 \mathrm{q} 34.1 / 22 \mathrm{q} 11.2$ \\
\hline 7 & A. K. & 62 & $\mathrm{~F}$ & 850 & $9 \mathrm{q} 34.11 / 22 \mathrm{q} 11.21$ \\
\hline $8 \mathrm{~b}$ & M. M. & 55 & $F$ & 550 & $9 q 34.1 / 22 q 11.2$ \\
\hline 9 & T. M. & 55 & M & 550 & $9 \mathrm{q} 34.1 / 22 \mathrm{q} 11.2$ \\
\hline 10 & C. T. & 49 & $\mathrm{~F}$ & 550 & $9 \mathrm{q} 34.1 / 22 \mathrm{q} 11.2$ \\
\hline 11 & $\mathrm{~K} . \mathrm{O}$. & 58 & M & 850 & $9 \mathrm{q} 34.11 / 22 \mathrm{q} 11.21$ \\
\hline 12 & M. Y. & 49 & $\mathbf{F}$ & 650 & $9 \mathrm{q} 34.1 / 22 \mathrm{q} 11.2$ \\
\hline 13 & M. H. & 47 & M & 650 & $9 \mathrm{q} 34.1 / 22 \mathrm{q} 11.2$ \\
\hline 14 & I. I. & 74 & $\mathrm{M}$ & 550 & $9 \mathrm{q} 34.1 / 22 \mathrm{q} 11.21$ \\
\hline 15 & S. S. & 29 & M & 850 & $9 \mathrm{q} 34.11 / 22 \mathrm{q} 11.21$ \\
\hline 16 & $\mathrm{~K} \cdot \mathrm{M}$. & 42 & M & 850 & $9 \mathrm{q} 34.11 / 22 \mathrm{q} 11.21$ \\
\hline 17 & $\mathrm{~T} . \mathrm{O}$ & 44 & $\mathrm{M}$ & 550 & $9 \mathrm{q} 34.1 / 22 \mathrm{q} 11.2$ \\
\hline $18 b$ & M. C. & 27 & $\mathrm{~F}$ & 550 & $9 \mathrm{q} 34.1 / 22 \mathrm{q} 11.2$ \\
\hline 19 & M. M. & 42 & $F$ & 850 & $9 \mathrm{q} 34.11 / 22 \mathrm{q} 11.21$ \\
\hline
\end{tabular}

Jpn. J. Human Genet. 
case $1, \mathrm{t}(4 ; 9 ; 22)(\mathrm{q} 33 ; \mathrm{q} 34.1 ; \mathrm{q} 11.2)$ in case $6, \mathrm{t}(9 ; 22 ; 12)(\mathrm{q} 34.1 ; \mathrm{q} 11.2 ; \mathrm{q} 24.1)$ in case 8 , and $\mathrm{t}(9 ; 22 ; 12)$ (q34.1; $11.2 ; \mathrm{p} 13.1)$ in case 18 .

Among 19 patients examined, 14 patients were analyzed at early metaphase stage of mitosis (approximately 550-650 bands per haploid set of chromosomes) (Yunis, 1981). The breakpoints of the $\mathrm{Ph}$ translocation were found to be $9 \mathrm{q} 34.1$ and $22 \mathrm{q} 11.2$ on chromosome $\$ 9$ and $\# 22$, respectively. In five cases the breakpoints were specified with prometaphase cells (approximately 850 bands per haploid set) (Fig. 1). The chromosome segment translocated from the terminal portion of chromosome $\# 9$ to chromosome $\# 22$ showed two dark bands: They were $9 \mathrm{q} 34.12$ proximally and $9 \mathrm{q} 34.2$ distally. Whereas, the segment translocated from the Ph chromosome to the $9 \mathrm{q}+$ chromosome showed two moderately dark bands proximally (22q12.1 and 22q12.3) and two narrow bands distally (22q13.2 and 22q13.32). The band $22 q 11.22$ which is a thin and weakly positive band and can originally be seen close to the band $\mathrm{q} 12.1$, could not be recognized on the $\mathrm{Ph}$ chromosome but seemed

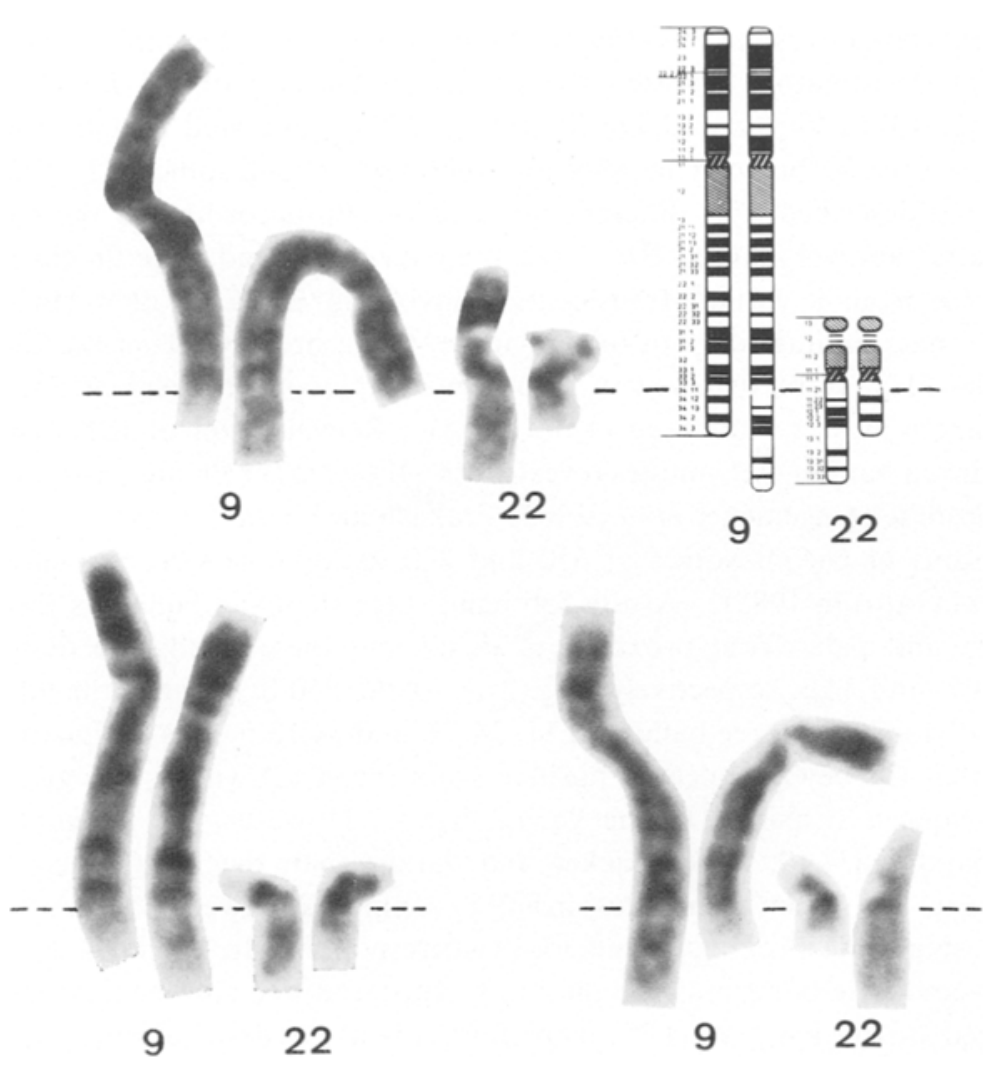

Fig. 1. Partial karyotypes of chromosomes $\$ 9$ and $\$ 22$ from case 11 (top), case 19 (bottom left), and case 16 (bottom right). Diagram and band designation are quoted from ISCN (1985). 
to be present on the $9 q+$ chromosome distal to the pale region where rejoining occurred. In addition, the dark band which is seen very close to $22 \mathrm{q} 11.1$ band on the long arm of the $\mathrm{Ph}$ chromosome was well corresponded to $9 \mathrm{q} 34.12$ band in its staining darkness and width. Thus, the breakpoint of the $\mathrm{Ph}$ chromosome was assigned to $22 \mathrm{q} 11.21$.

\section{DISCUSSION}

The breakpoints of the $\mathrm{Ph}$ translocation were identical in all the 19 cases of Ph-positive CML. The breakpoints were $9 q 34.1$ and $22 q 11.2$ with early metaphase cells and $9 \mathrm{q} 34.11$ and $22 \mathrm{q} 11.21$ at prometaphase stage. Previous studies in which the $\mathrm{Ph}$ translocations were studied with high resolution banding of methotrexate synchronization culture showed that the breakpoints were the same as we identified in this study (Prakash and Yunis, 1984; Mohamed et al., 1986). These results indicate that the breakage and reunion of the Ph translocation occur at identical bands in all patients regardless the $\mathrm{Ph}$ is derived from a standard or a complex translocation.

Several investigators reported the variety in the size of the $\mathrm{Ph}$ chromosome (Watt et al., 1977; Verma and Dosik, 1980). They suggested that the breakpoint may not be specific but can happen anywhere on chromosome $\# 22$. Verma and Dosik (1980) described four different types of the Ph according to the size; small, average, large, and very large. However, their very large and large $\mathrm{Ph}$ chromosomes were derived from a variant translocation involving \#22 and other chromosomes than \#9. These findings are not incompatible with a breakpoint on the $22 \mathrm{q} 11$ band because the $\mathrm{Ph}$ may be involved in a further complex rearrangement and becomes actually larger in size (Sandberg et al., 1985). Reevaluation of these cases using high resolution banding techniques revealed that these larger $\mathrm{Ph}$ are a form of masked Ph chromosome (Hagemeijer et al., 1984; Prakash and Yunis, 1984).

Diagrams of chromosomes at 550 and 850 band stage were presented by the ISCN (1981) (also in 1985). At the 550 band stage the band 9q34 has three bands, pale, dark, and pale, from proximal to distal and these bands are designated as $9 \mathrm{q} 34.1,34.2$, and 34.3 , respectively (Fig. 2). At the 850 band stage the $9 \mathrm{q} 34.1$ band is further divided into three bands, $34.11,34.12$, and 34.13. This designation system indicates that the newly appeared positive band $(9 q 34.12)$ will be recognized within the band $9 \mathrm{q} 34.1$, proximal to the $9 \mathrm{q} 34.2$ band. However, the proximal Giemsa positive band, $9 \mathrm{q} 34.12$, looks thicker and darker than the distal one, $9 \mathrm{q} 34.2$, as shown in Fig. 2. When a chromosome $\# 9$ is compared between 550 band stage and 850 band stage, the proximal band looks corresponding to the $9 q 34.2$. Thus the distal thin and pale band must be the newly appeared one so that this band should be localized in the band $9 \mathrm{q} 34.3$. Therefore, when the designation system recommended by the ISCN is applied to, these five bands which can be recognized at 850 band stage have to be designated as $9 \mathrm{q} 34.1,34.2,34.31,34.32$, and 34.33 , respectively, as it has already been proposed by Yunis (1980). 


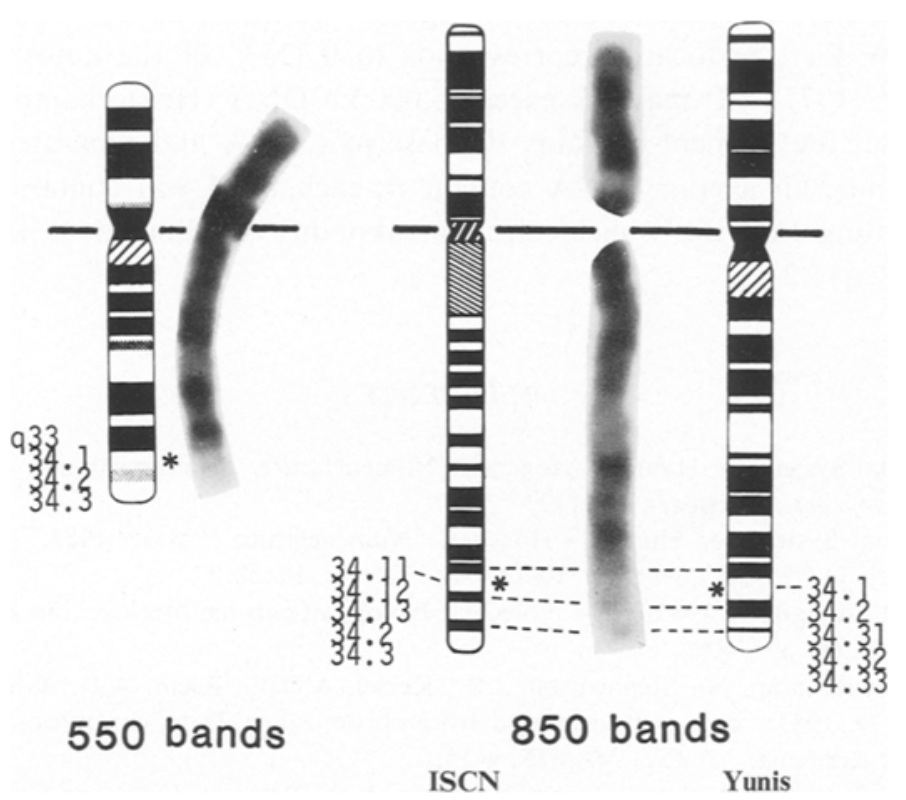

Fig. 2. Chromosome $\# 9$ at 550 band stage and at 850 band stage. Diagrams of 550 bands and 850 bands of the left side are quoted from ISCN (1985). Diagram of 850 bands on the right is proposed by Yunis (1980). Asterisks indicate the pale band where breakage and reunion occur on $9 \mathfrak{q}+$ chromosome.

These two different interpretations of the chromosome bands arise a problem in specifying the breakpoints of the $\mathrm{Ph}$ translocation because the breakpoint on chromosome $\# 9$ exists in the most proximal pale band in the band $9 \mathrm{q} 34$ (Fig. 2). This band is designated as $9 \mathrm{q} 34.11$ according to the ISCN but is $9 \mathrm{q} 34.1$ by a proposal of Yunis and the latter seems correct as discussed above. The other breakpoint of the $P h$ translocation is $22 q 11.21$ at 850 band stage and $22 q 11.2$ at 550 band stage.

Recent studies using molecular biology techniques demonstrated that the exact breakpoint is not point-specific and is not always an identical site. The breakpoints on chromosome $\# 22$ are clustered within an approximately 5.8-kilobase-pair region termed breakpoint cluster region or bcr (Groffen et al., 1984). Moreover, the breakpoint on chromosome $\# 9$ exists in a relatively large but limited region and the break occurs over a minimum range of $50-100 \mathrm{~kb}$ (Heisterkamp et al., 1983; Gale and Cannani, 1985).

A human nuclear DNA was estimated to contain approximately $3.3 \times 10^{9} \mathrm{nu}$ cleotides. Even when chromosomes are analyzed at prometaphase stage (approximately 850 bands per haploid), each chromosome band still contains an average of $2 \times 10^{6}$ base pairs (1-5,000 kb of DNA) (Gale and Cannani, 1985). Another esti- 
mation suggested that the chromosome segment translocated from chromosome $\# 9$ to \#22 in the $\mathrm{Ph}$ translocation corresponds to $0.325 \%$ of the autosomal genome (Hayall et al., 1977). It may not exceed 5,000 kb DNA (Heisterkamp et al., 1983). Assuming that the segment contains $10^{7}$ base pair DNA and separates into 5 dark and pale bands, an average DNA content in each band will contain $2 \times 10^{6}$ base pairs, suggesting that the translocation breakpoints are limited to a single band $9 \mathrm{q} 34.1$ and $22 \mathrm{q} 11.21$.

\section{REFERENCES}

An International System for Human Cytogenetic Nomenclature. High-resolution Banding (1981). 1981. Cytogenet. Cell Genet. 31: 1-23.

An International System for Human Cytogenetic Nomenclature (1985). 1985. Harnden, D.G. and Clinger, H.P., eds., Cytogenet. Cell Genet., Karger, Basel.

Gale, R.P. and Cannani, E. 1985. The molecular biology of chronic myelogenous leukaemia. $B r$. J. Haematol. 60: $395-408$.

Groffen, J., Heisterkamp, N., Stephemson, J.R., Kessel, A.G.V., Klein, A.D., Grosveld, G., and Bootsma, D. 1983. c-sis is translocated from chromosome 22 to chromosome 9 in chronic myelocytic leukemia. J. Exp. Med. 15: 9-15.

Groffen, J., Stephenson, J.R., Heisterkamp, N., Klein, A.D., Bartram, C.R., and Grosveld, G. 1984. Philadelphia chromosomal breakpoints are clustered within a limited region, bcr, on chromosome 22. Cell 36: 93-99.

Hagemeijer, A., Bartram, C.R., Smit, E.M.E., Agthoven, A.J.V., and Bootsma, D. 1984. Is the chromosomal region $9 \mathrm{q} 34$ always involved in variants of the $\mathrm{Ph}^{1}$ translocation? Cancer Genet. Cytogenet. 13: 1-16.

Hayall, B.H., Carrano, A.V., Moor, D.H., II., and Rowley, J.D. 1977. Quantification by DNAbased cytophotometry of the $9 q+/ 22 q-$ chromosomal translocation associated with chronic myelogenous leukemia. Cancer Res. 37: 3590-3593.

Heisterkamp, N., Stephenson, J.R., Groffen, J., Hansen, P.F., Klein, A.D., Bartram, C.R., and Grosveld, G. 1983. Localization of the c-abl oncogene adjacent to translocation break point in chronic myelocytic leukaemia. Nature 306: 239-242.

Klein, A.D., Kessel, A.G.V., Grosvels, G., Bartram, C.R., Hagemeijer, A., Bootsma, D., Spurr, N.K., Heisterkamp, N., Groffen, J., and Stephenson, J.R. 1982. A cellular oncogene is translocated to the Philadelphia chromosome in chronic myelocytic leukaemia. Nature 300: 765767.

Misawa, S., Horiike, S., Taniwaki, M., Abe, T., and Takino, T. 1986. Prefixation treatment with ethidium bromide for high-resolution banding analysis of chromosomes from cultured human bone marrow cells. Cancer Genet. Cytogenet. 22: 319-329.

Mitelman, F. 1985. Catalog of chromosome aberrations in cancer. Progress and Topics in Cytogenetics, Vol. 5, Sandberg, A.A., Series ed., Alan R. Liss, Inc., New York.

Mohamed, A.N., Clarkson, B.D., and Chaganti, R.S.K. 1986. High resolution banding of chronic myeloid leukemia chromosomes. Cancer Genet. Cytogenet. 20: 209-222.

Nowell, P.C. and Hungerford, D.A. 1960. A minute chromosome in human chronic granulocytic leukemia. Science 132: 1497.

Prakash, O. and Yunis, J.J. 1984. High resolution chromosomes of the $t(9 ; 22)$ positive leukemia. Cancer Genet. Cytogenet. 11: 361-367.

Rowley, J.D. 1973. A new consistent chromosomal abnormality in chronic myelogenous leukaemia identified by quinacrine fluorescence and Giemsa staining. Nature 243: 290-293. 
Sandberg, A.A., Morgan, R., Kipps, T.J., Hecht, B.K., and Hecht, F. 1985. The Philadelphia (Ph) chromosome in leukemia. II. Variant $\mathrm{Ph}$ translocations in acute lymphoblastic leukemia. Cancer Genet. Cytogenet. 14: 11-21.

Verma, R.S. and Dosik, H. 1980. Heteromorphism of the Philadelphia $\left(\mathrm{Ph}^{1}\right)$ chromosome in patients with chronic myelogenous leukemia (CML). I. Classification and clinical significance. Br. J. Haematol. 45: 215-222.

Watt, J.L., Hamilton, P.J., and Page, B.M. 1977. Variation in the Philadelphia chromosome. Hum. Genet. $37: 141-148$.

Yunis, J.J. 1980. Nomenclature for high resolution human chromosomes. Cancer Genet. Cytogenet. 2: 221-229.

Yunis, J.J. 1981. Chromosomes and cancer: New nomenclature and future directions. Hum. Pathol. 12: 494-502. 